\title{
The Effect of Dorsal Midbrain Compression by the Posterior third Ventricular Cyst on Frontal EEG Under Propofol Anesthesia
}

\author{
Ramamani Mariappan ${ }^{1}$ Sruthi Yalamanchili² Krishna Prabhu ${ }^{3} \quad$ Sharon Poldoss ${ }^{1}$ \\ ${ }^{1}$ Department of Neuroanaesthesia, Christian Medical College, \\ Vellore, Tamil Nadu, India \\ 2Department of Anaesthesia, Christian Medical College, Vellore, \\ Tamil Nadu, India \\ Address for correspondence Ramamani Mariappan, MD, \\ Department of Neuroanaesthesia, Christian Medical College, \\ Vellore 632004, Tamil Nadu, India (e-mail: ramamani@ \\ cmcvellore.ac.in).
}

${ }^{3}$ Department of Neurological Sciences, Christian Medical College, Vellore, Tamil Nadu, India

J Neuroanaesthesiol Crit Care 2022;9:56-57.

A 25-year-old, American Society of Anesthesiologists (ASA)-1 male patient (body mass index [BMI] 24) presented with a posterior third ventricular cyst, causing mass effect on midbrain and cerebellum and leading to tonsillar herniation and medullary compression with a cervical syrinx ( - Fig. 1). He underwent midline suboccipital craniotomy (MSOC) and excision of the posterior third ventricular cyst with $\mathrm{C} 1 \mathrm{arch}$ excision in Concorde position. At admission, his Glasgow coma scale (GCS) score was 15/15 with normal higher mental functions. He had a divergent squint with upgaze palsy, absent accommodation reflex, and preserved light reflex with apparent enophthalmos. He had normal power in all limbs with increased tone on the right limbs, resulting in a spastic hemiplegic gait. He had restrictive lung disease (RLD) with a single breath count of 15 due to tonsillar herniation with the cervical syrinx. Arterial blood gas (ABG) test done showed a $\mathrm{PaCO}_{2}$ of $48 \mathrm{~mm} \mathrm{Hg}$ and $\mathrm{PaO}_{2}$ of $82 \mathrm{~mm} \mathrm{Hg}$.

After attaching the standard ASA monitors, anesthesia was induced with propofol $(2.5 \mathrm{mg} / \mathrm{kg})$ and fentanyl (2 ug/ $\mathrm{kg})$. Vecuronium $(0.1 \mathrm{mg} / \mathrm{kg}$ ) was administered to facilitate tracheal intubation with a flexometallic endotracheal tube. Depth of anesthesia (DOA) was monitored using a four-channel frontal EEG monitor (SedLine Sedation Monitor, Masimo). Anesthesia was maintained with propofol and fentanyl infusion to facilitate motor-evoked potential (MEP) monitoring. Propofol dose was titrated to EEG, spectrogram pattern, and patient state index (PSI) (25-50) on the SedLine brain function monitor. Mean arterial pressure (MAP) was maintained within $10 \%$ of baseline. Normothermia was maintained throughout the procedure. The surgery was started with $\mathrm{C} 1$ arch excision and then proceeded with MSOC. From the time of induction till the $\mathrm{C} 1$ arch excision, PSI remained

published online

August 02, 2021
DOI https://doi.org/

$10.1055 / \mathrm{s}-0041-1731147$ ISSN 2348-0548 low (18-22) with frequent burst suppression despite reducing the propofol gradually from 120 to $70 \mu \mathrm{g} / \mathrm{kg} / \mathrm{min}$ (-Fig. 2). After the excision of $\mathrm{C} 1$ arch, the PSI gradually increased from 21 to 29 and the requirement of propofol also increased from 70 to $100 \mu \mathrm{g} / \mathrm{kg} / \mathrm{min}$. After the MSOC bone flap removal, the PSI increased further to 35 and finally to 39 despite increasing the dose of propofol to 120 to $130 \mu \mathrm{g} / \mathrm{kg} / \mathrm{min}$. The frontal EEG and the spectrogram did not show burst suppression despite increasing the dose of propofol. After the dural opening, the PSI increased from 39 to 43 and the propofol requirement further increased from 130 to $140 \mu \mathrm{g} / \mathrm{kg} / \mathrm{min}$ (-Fig. 2). From the time of tumor excision till end of surgery, there was no major fluctuations in PSI or the propofol requirement $(120-140 \mu \mathrm{g} / \mathrm{kg} / \mathrm{min})$. Postoperatively, the patient was assessed for intraoperative awareness using modified Brice questionnaire and there was no awareness or recall of

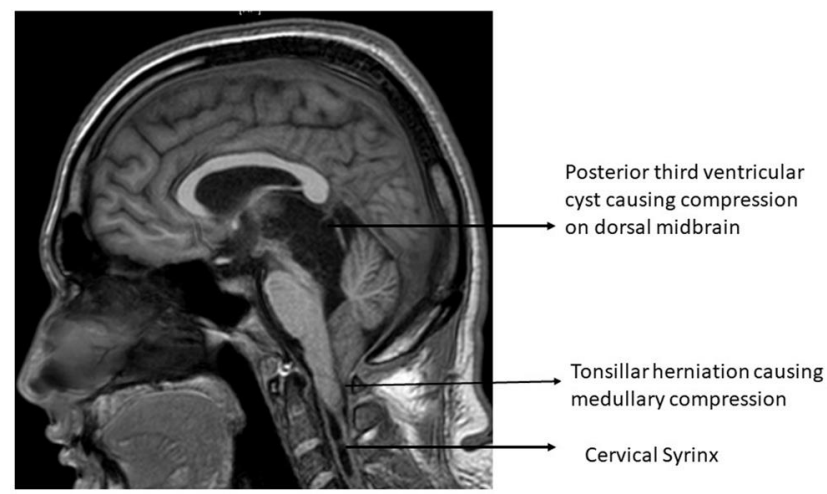

Fig. 1 MRI brain (T1-weighted [T1W] image)-sagittal view showing the posterior third ventricular cyst, causing dorsal midbrain compression and tonsillar herniation with cervical syrinx. (c) 2021. Indian Society of Neuroanaesthesiology and Critical Care. All rights reserved.

This is an open access article published by Thieme under the terms of the Creative Commons Attribution-NonDerivative-NonCommercial-License, permitting copying and reproduction so long as the original work is given appropriate credit. Contents may not be used for commercial purposes, or adapted, remixed, transformed or built upon. (https://creativecommons.org/licenses/by-nc-nd/4.0/).

Thieme Medical and Scientific Publishers Pvt. Ltd. A-12, 2nd Floor, Sector 2, Noida-201301 UP, India 


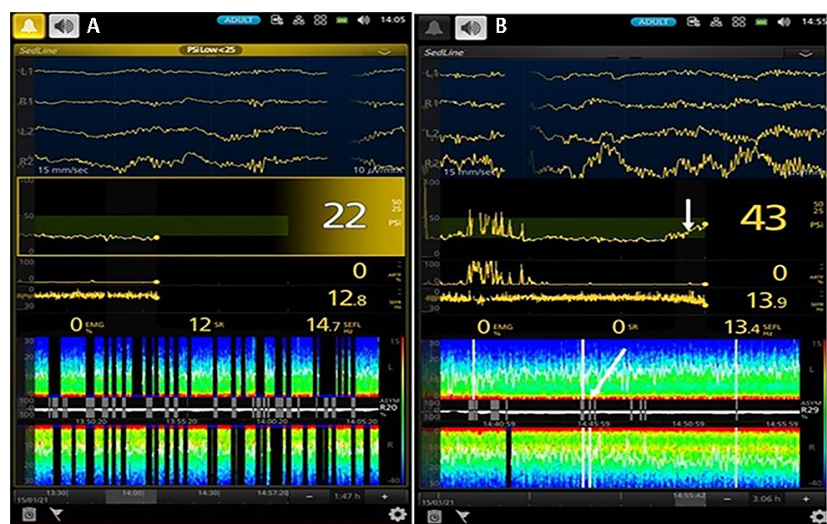

Fig. 2 Four-channel EEG, patient state index (PSI) value, and the spectrogram pattern during different stages of surgery under varying doses of propofol anesthesia. (A) After turning prone, during surgical exposure. EEG: Slowing/flattening; PSI: Showing low value (21-22); Spectogram: Showing frequent burst suppression, despite reducing the propofol from 120 to 80 then to $70 \mu \mathrm{g} / \mathrm{kg} / \mathrm{min}$. (B) After the dural opening (arrow). EEG: Persistent EEG activity with no flattening; PSI: Gradually improved to 43; Spectogram: No suppression pattern seen, despite increasing the propofol dose to $130-140 \mu \mathrm{g} / \mathrm{kg} / \mathrm{min}$.

intraoperative events. There was no delirium or cognitive dysfunction noted during the postoperative period.

We believe that chronic dorsal midbrain (DMB) compression decreases the cortical inputs from the brainstem, leading to hyperpolarization of cortical pyramidal neurons with the appearance of slow delta oscillation on EEG. Jennet et al, in their experimental animal studies, had shown the effect of midbrain compression on pupillary size, cardiorespiratory parameter, and EEG activity. They had shown that midbrain compression produces a slowing or flattening effect on EEG despite the heart rate and blood pressure being stable and the temperature being normal, similar to our finding. ${ }^{1}$ Fukuda et al studied the behavioral and the EEG alterations in animals with brainstem compression and have shown that the brain stem compression caused flattened and/or spike pattern, and then shifting of this pattern into high-amplitude slow waves. ${ }^{2}$ In our case, we had applied the frontal EEG sensor only after the endotracheal intubation, and hence the EEG pattern was not observed in an awake state. From the start of surgery till the bone flap removal, despite the vitals and the temperature being within normal limits, the EEG showed frequent suppression, even with a reduced dose of propofol. Following the bone flap removal and dural opening, there was a significant improvement in the EEG pattern and the PSI with a significant increase in propofol dose requirement.

For a patient with dorsal midbrain compression, the conduct of anesthesia using an age-appropriate anesthetic dose could lead to deep anesthesia with prolonged burst suppression on EEG. The prolonged period of burst suppression can lead to adverse outcomes after anesthesia. Studies have shown that the duration of EEG suppression correlates with postoperative ventilation, delirium, and cognitive dysfunction. ${ }^{3-5}$ The reliability of processed EEG for monitoring the DOA in the presence of dorsal midbrain compression is not reported in the literature.

In our case, titrating the anesthetic dose based on DOA monitor helped us to assess the neurological status at the end of surgery without any adverse events (postoperative cognitive dysfunction or delirium). Administration of low dose propofol $(70 \mu \mathrm{g} / \mathrm{kg} / \mathrm{min})$ till the bone flap elevation did not lead to a recall of intraoperative events, implying that titration of anesthesia using DOA monitor is essential to avoid prolonged burst suppression on EEG in patients with $\mathrm{DMB}$ compression. In future, large prospective studies are warranted to study the reliability of DOA monitors for titrating the intraoperative anesthetic dose and its effect on postoperative outcome (neurological and non-neurological) in patients with DMB compression.

\section{Conflict of Interest}

None declared.

\section{References}

1 Jennett WB, Stern WE. Tentorial herniation, the mid brain and the pupil. Experimental studies in brain compression. J Neurosurg 1960;17:598-609

2 Fukuda N, Saji Y, Nagawa Y. [Behavioral and EEG alterations with brain stem compression and effect of thyrotropin-releasing hormone (TRH) in chronic cats (author's transl)]. Nippon Yakurigaku Zasshi 1979;75(4):321-331

3 Petsiti A, Tassoudis V, Vretzakis G, et al. Depth of anesthesia as a risk factor for perioperative morbidity. Anesthesiol Res Pract 2015;2015:829151

4 Fritz BA, Kalarickal PL, Maybrier HR, et al. Intraoperative electroencephalogram suppression predicts postoperative delirium. Anesth Analg 2016;122(1):234-242

5 Hesse S, Kreuzer M, Hight D, et al. Association of electroencephalogram trajectories during emergence from anaesthesia with delirium in the postanaesthesia care unit: an early sign of postoperative complications. Br J Anaesth 2019;122(5):622-634 